\title{
Homoisoflavanone-1 isolated from Polygonatum odoratum arrests the cell cycle and induces apoptosis in A549 cells
}

\author{
DELI NING, MING JIN, TAO XV, JIKAI SUN and MIN LI
}

Department of Pharmacy, The Institute of Medicine, Qiqihar Medical University, Qiqihar, Heilongjiang 161006, P.R. China

Received December 18, 2017; Accepted June 28, 2018

DOI: $10.3892 / \mathrm{ol} .2018 .9085$

\begin{abstract}
Homoisoflavanone-1 is a natural compound that may be extracted from the Chinese medicinal herb Polygonatum odoratum, which has pronounced antioxidant activities. The present study reports that homoisoflavanone-1 significantly inhibited tumor cell growth and induced apoptosis in A549 non-small cell lung cancer (NSCLC) cells in a dose-dependent manner. Homoisoflavanone-1 arrested the cell cycle at the G2/M stage, which was associated with an increase in the accumulation of phosphorylated (p-)p38, p38, $\mathrm{p} 53$, and p-cyclin dependent kinase $(\mathrm{Cdc}) 2$ proteins, as well as a decrease in $\mathrm{Cdc} 2$ expression. In addition, treatment with homoisoflavanone-1 increased the levels of active caspase-3 and decreased Poly ADP-ribose polymerase, which was accompanied by a reduction in the B-cell lymphoma-2/Bak ratio and consequently, apoptosis. Furthermore, homoisoflavanone-1 increased the expression of endoplasmic reticulum (ER) stress-related proteins, including PERK, ATF4 and GADD34 in a dose-dependent manner. In conclusion, homoisoflavanone-1 induced apoptosis in A549 cells by regulating the mitochondria-caspase-dependent and ER stress pathways and resulted in G2/M arrest by activating the p38/p53 signaling pathway. These findings suggest that homoisoflavanone-1 extracted from Polygonatum odoratum may function as a cancer-suppressing agent and has potential as a novel therapeutic method against NSCLC.
\end{abstract}

\section{Introduction}

Lung cancer is the leading cause of death forboth men and women in many countries (1). Non-small cell lung cancer (NSCLC) accounts for approximately $85 \%$ of lung cancer cases (2). Surgery is the most effective treatment for NSCLC if the cancer is diagnosed early. However, up to $75 \%$ of patients are diagnosed with NSCLC at an advanced disease $(3,4)$. Although

Correspondence to: Dr Deli Ning, Department of Pharmacy, The Institute of Medicine, Qiqihar Medical University, 333 Bukuibei Road, Qiqihar, Heilongjiang 161006, P.R. China

E-mail: ningdeli@qmu.edu.cn

Key words: homoisoflavanone-1, A549 cells, apoptosis, immunoblot there has been some progress in methods for diagnosis and treatment, the prognosis of the patients with NSCLC has not improved much, and the 5-year survival rate is currently less than $15 \%$ (5). Therefore, there is a need to develop new and safe therapeutic agents against NSCLC.

Conventional chemotherapies kill normal cells in addition to cancer cells by inducing cell cycle checkpoint arrest or apoptosis. The initiation of apoptosis is tightly regulated by intrinsic caspase-dependent pathways (including one that is mitochondrion-dependent) and extrinsic caspase-dependent pathways (such as the death receptor-induced caspase activation pathway) (6,7). A shared a terminal execution pathway begins with caspase-3 cleavage and ultimately leads to phagocytosis (8). The best characterized regulators of apoptosis are the Bcl-2 family of proteins, which promote or repress apoptosis by directly regulating a mitochondrial apoptosis-induced channel. The multidomain pro-apoptotic protein $\mathrm{Bax} / \mathrm{Bak}$ is responsible for forming this channel, while Bcl-2, Bcl-xL, or Mcl-1 inhibit its formation $(9,10)$. Additionally, the intrinsic ER stress pathway is triggered by conditions that disturb protein folding in the endoplasmic reticulum (ER). The induction of the ER stress pathway may contribute to cell death by activating the IRE1 kinase via activation of APOPTOTIC-SIGNALING KINASE (ASK) and p38 MAPK, which itself activates CHOP by phosphorylating the CHOP transactivation domain (11). Additionally, both p38 MAPK and the Jun-N-terminal kinase (JNK) were reported to promote phosphorylation and activation of Bak (12). In addition, Bax and Bak induce cell death by binding and activating INOSITOL-REQUIRING PROTEIN-1 $\alpha$ (IRE1 $\alpha$ ) (13). Intriguingly, accumulating evidence indicates that activated p38 can cause mitotic arrest in the somatic cell cycle at the spindle assembly checkpoint (14).

Traditional herbal medicines with anti-cancer properties that trigger apoptosis in various types of tumor cells with minimal adverse effects have been valuable sources for therapeutic agents. Polygonatum odoratum is widely used as an herbal medicine with procoagulant (15), anti-hyperglycemic (16), anti-herpes simplex virus-II, and apoptosis-inducing (17) activities, that can also improve glucose tolerance (18). However, the active components in $P$. odoratum for the anti-cancer effects and the underlying mechanisms of these effects remain largely unknown.

Homoisoflavanone-1 is a type of phenolic compound isolated from $P$. odoratum that has apparent antioxidant 
activities $(19,20)$. However, the effects of homoisoflavanone-1 on human NSCLC cells, and therefore the mechanism of this effect, have never been elucidated. In the present study, we investigated the effect of homoisoflavanone-1 on NSCLC A549 cell proliferation and cell cycle progression. Our result shows that homoisoflavanone-1 has potential as a new natural anti-tumor medicine for treatment of NSCLC.

\section{Materials and methods}

Cell culture and reagents. The human NSCLC cell line A549 was purchased from Basic medical cell center of Peking Union Medical College (Peking, China). A549 cells were cultured in DMEM containing 10\% fetal bovine serum (Gibco; Thermo Fisher Scientific, Inc., Waltham, MA, USA), $1 \%$ penicillin, and $1 \%$ streptomycin in $5 \% \mathrm{CO}_{2}$ at $37^{\circ} \mathrm{C}$. Cells in the exponential phase were used in the experiments.

Dimethyl sulfoxide (DMSO) and 3-(4,5-dimethylthiazol-2-yl)-2,5-diphenyltetrazolium bromide (MTT) were purchased from Amresco, LLC, (Solon, OH, USA) and Propidium iodide (PI)/Annexin V-FITC was obtained from Sigma-Aldrich; Merck KGaA, (Darmstadt, Germany). Polyclonal antibodies against Caspase 3, Active caspase 3, Bak, Bcl-2, p-p38, p38, p53, Cdc2, p-Cdc2, $\beta$-actin, and the horseradish peroxidase-conjugated secondary antibody were bought from Cell Signaling Technology, Inc., (Danvers, MA, USA).

Isolation and purification of homoisoflavanone-1. The homoisoflavanone-1 used in this study was extracted and purified from $P$. odoratum roots (Fig. 1A) according to the methods described previously with appropriate modification (20). Briefly, $10 \mathrm{~kg}$ of dried $P$. odoratum roots was ground and subjected to two $95 \%$ ethanol extractions at room temperature. The solvent was removed under reduced pressure, and the concentrate was diluted in water, followed by filtering. The precipitate including insoluble metabolites was dissolved in 90\% methanol. The methanol-soluble fraction was collected and subjected to chromatography on a silica gel column, with a gradient of petroleum ether and petroleum ether-ethyl acetate as the eluting solvent, followed by thin layer chromatography to collect cytotoxic fractions. Based on HPLC analysis of the collected components, an elution with a single component was collected. Homoisoflavanone-1 (17.84 mg) was isolated by reverse-phase preparative HPLC, using methanol: $\mathrm{H}_{2} \mathrm{O}$ (60:40) as the mobile phase, and was identified by comparing ESI-MS/MS and spectroscopic $\left({ }^{1} \mathrm{H}-\mathrm{NMR}\right.$ and $\left.{ }^{13} \mathrm{C}-\mathrm{NMR}\right)$ data.

The structures of homoisoflavanone-1 were in good agreement with a previous report (20) of it being 5,7-dihydroxyl-6-met hyl-8-methoxyl-3-(4'-hydroxylbenzyl)-chroman-4-one (Fig. 1B).

Cell viability assay. The effect of homoisoflavanone-1 on A549 cell viability was determined using the MTT assay. Briefly, cells were incubated in 96 -well plates at a density of $10 \times 10^{4}$ per well for $24 \mathrm{~h}$ before treatment with homoisoflavanone-1 or DMSO, as the control. Homoisoflavanone-1 was dissolved in DMSO at serial concentrations $(12.5,25,50$, and $100 \mu \mathrm{g} / \mathrm{ml})$, and $8 \mu \mathrm{l}$ of these solutions were added to each well and the samples were incubated for 6,12 , and $24 \mathrm{~h}$. The results were read using a microplate spectrophotometer (BioTek Instruments,
Inc., Winooski, VT, USA) at $570 \mathrm{~nm}$. The rate of cell growth inhibition (\%) was calculated as: [1-A549 experiment group OD/A549 control OD] x100\%. The half maximal inhibitory concentration $\left(\mathrm{IC}_{50}\right)$ values were determined by plotting a linear regression curve.

Colony formation assay. A549 cells were seeded in triplicate into 12-well tissue culture plates and cultured for 6 days after treatment with homoisoflavanone-1 at serial concentrations $(12.5,25,50$, and $100 \mu \mathrm{g} / \mathrm{ml})$. Then, crystal violet was used for staining, and the rate of colony formation was calculated.

Cell cycle analysis. A549 cells were seeded into 6-well plates, incubated for $12 \mathrm{~h}$, and then treated with either homoisoflavanone-1 $(12.5,25,50$, or $100 \mu \mathrm{g} / \mathrm{ml})$ or DMSO for $24 \mathrm{~h}$. Cells were collected, fixed in $70 \%$ ethanol, centrifuged $(3,000 \mathrm{~g}$, $5 \mathrm{~min}$ ) and washed twice with ice-cold PBS. The cells were stained with PI for $20 \mathrm{~min}$ at $4^{\circ} \mathrm{C}$ in the dark. Cell cycle analysis was carried out with a fluorescence-activated cell sorting (FACS) Calibur flow cytometer (BD FACSCalibur; BD Biosciences, Franklin Lakes, NJ, USA USA).

Cell apoptosis analysis. Apoptosis analyses were performed with an Annexin Vfluorescein isothiocyanate (FITC) apoptosis detection kit (BioVision, Inc., Milpitas, CA, USA). A549 cells were seeded in 96-well plates, incubated for $12 \mathrm{~h}$, and then treated with homoisoflavanone-1 $(12.5,25,50$, or $100 \mu \mathrm{g} / \mathrm{ml})$ for $24 \mathrm{~h}$. Cells were collected and washed twice with ice-cold PBS, followed by incubation with Annexin-V for $10 \mathrm{~min}$ in the dark. Next, the cells were incubated with PI for $5 \mathrm{~min}$ and evaluated for apoptosis using a FACS Calibur flow cytometer (BD FACSCalibur; BD Biosciences).

Immunoblot analysis. A549 cells were seeded in 6-well plates for $12 \mathrm{~h}$, and then treated with either homoisoflavanone-1 $(12.5,25,50$, or $100 \mu \mathrm{g} / \mathrm{ml})$ or DMSO for $24 \mathrm{~h}$. Cellular proteins were harvested and immunoblotting was carried out as previously described (21) with appropriate modifications. Cells were resuspended in lysis buffer (1\% Triton-X100, $50 \mathrm{mM}$ Hepes $\mathrm{pH}$ 7.4, $2 \mathrm{mM}$ sodium orthovanadate, $1 \mathrm{mM}$ edetic acid, $100 \mathrm{mM}$ sodium fluoride, $1 \mathrm{mM}$ PMSF, $10 \mu \mathrm{g} / \mathrm{ml}$ of leupeptin and $10 \mu \mathrm{g} / \mathrm{ml}$ of aprotinin), and the supernatants of the lysates were collected after centrifugation at $14,000 \mathrm{~g}$ for $10 \mathrm{~min}$ at $4^{\circ} \mathrm{C}$. The protein concentration was determined using a protein concentration kit. Proteins were separated with $12 \%$ sodium dodecyl sulfate-polyacrylamide gel electrophoresis and transferred to polyvinyldene fluoride membranes. The membranes were blocked in 5\% skimmed milk for $2 \mathrm{~h}$ at room temperature. Protein was detected with antibodies against active caspase 3, caspase 3, PARP, Bcl-2, Bak, p-Cdc2, $\mathrm{Cdc} 2, \mathrm{p}-\mathrm{P} 38, \mathrm{P} 38, \mathrm{P} 53$ or $\beta$-actin at $4^{\circ} \mathrm{C}$. The membranes were washed three times with TBST before incubation with the horseradish peroxidase-conjugated secondary antibody at room temperature for $1 \mathrm{~h}$. Immunoreactive bands were visualized using an ECL kit (Sigma-Aldrich; Merck KGaA). Protein levels were quantified relative to the control group.

Statistical analysis. All experiments were performed at least three independent times $(n=3)$, and data are presented as the mean \pm standard deviation (SD). The comparisons of multiple 
Table I. Effects of homoisoflavanone-1 on cell proliferation in lung cancer A549 cells.

\begin{tabular}{lccc}
\hline $\begin{array}{c}\text { Concentration } \\
(\mu \mathrm{g} / \mathrm{ml})\end{array}$ & $6 \mathrm{~h}$ & $12 \mathrm{~h}$ & $24 \mathrm{~h}$ \\
\hline 0 & $99.04 \pm 4.47$ & $123.15 \pm 9.50$ & $114.18 \pm 15.21$ \\
DMSO & $100.00 \pm 0.00$ & $100.00 \pm 0.00$ & $100.00 \pm 0.00$ \\
12.5 & $98.80 \pm 0.57$ & $93.54 \pm 26.32$ & $94.15 \pm 21.33$ \\
25 & $71.70 \pm 0.05$ & $67.47 \pm 22.90^{\mathrm{a}}$ & $67.14 \pm 25.07^{\mathrm{a}}$ \\
50 & $53.66 \pm 4.94^{\mathrm{b}}$ & $38.11 \pm 5.94^{\mathrm{a}}$ & $39.27 \pm 27.99^{\mathrm{b}}$ \\
100 & $22.86 \pm 4.84^{\mathrm{b}}$ & $11.78 \pm 5.61^{\mathrm{a}}$ & $7.51 \pm 1.22^{\mathrm{b}}$ \\
\hline
\end{tabular}

${ }^{\mathrm{a}} \mathrm{P}<0.05,{ }^{\mathrm{b}} \mathrm{P}<0.01$ vs. controls at the same time point. Data are shown as the mean \pm standard deviation from three independent experiments.

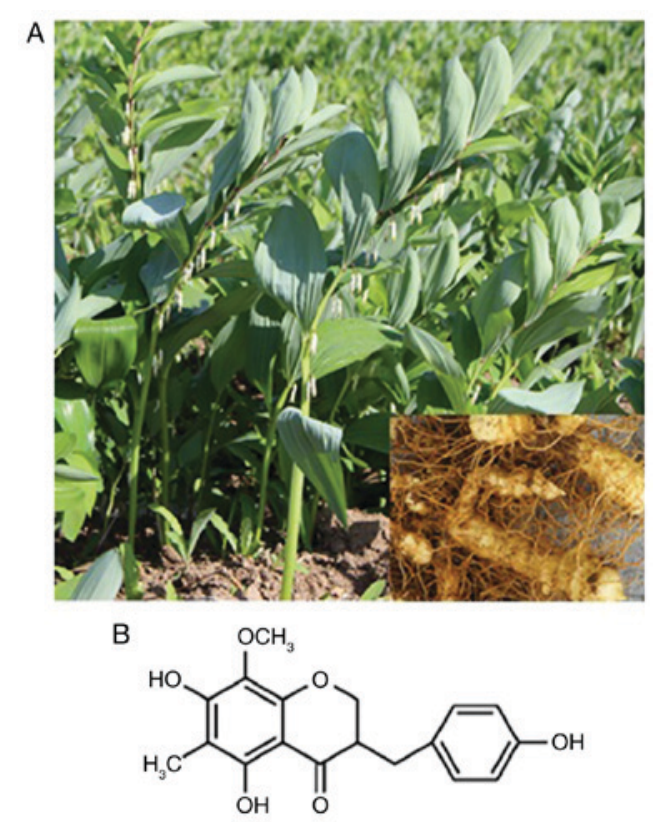

Figure 1. Structure of homoisoflavanone-1 extracted from the roots of Polygonatum odoratum. (A) Image of Polygonatum odoratum. (B) The structure of homoisoflavanone-1 was established via ${ }^{1} \mathrm{H}-\mathrm{NMR}$ and ${ }^{13} \mathrm{C}-\mathrm{NMR}$.

groups were performed using the one-way analysis of variance and the group differences were analyzed using Dunnett's post hoc tests. Statistical analyses were performed in SPSS v.13.0 (SPSS, Inc., Chicago, IL, USA) and $\mathrm{P}<0.05$ was considered to indicate a statistically significant difference.

\section{Results}

Homoisoflavanone-1 inhibits cell proliferation and colony formation of A549 Cells. An MTT assay was performed to determine the effect of homoisoflavanone-1 on the proliferation of A549 cells. As shown in Table I and Fig. 2A, homoisoflavanone-1 inhibited cell growth in a dose- and time-dependent manner. For example, a remarkable inhibitory effect was observed in cells treated with higher concentrations of homoisoflavanone-1 $(50,100 \mu \mathrm{g} / \mathrm{ml})$ for 6,12 , and $24 \mathrm{~h} \mathrm{vs}$. controls at the same time points $(\mathrm{P}<0.01)$, and a significant
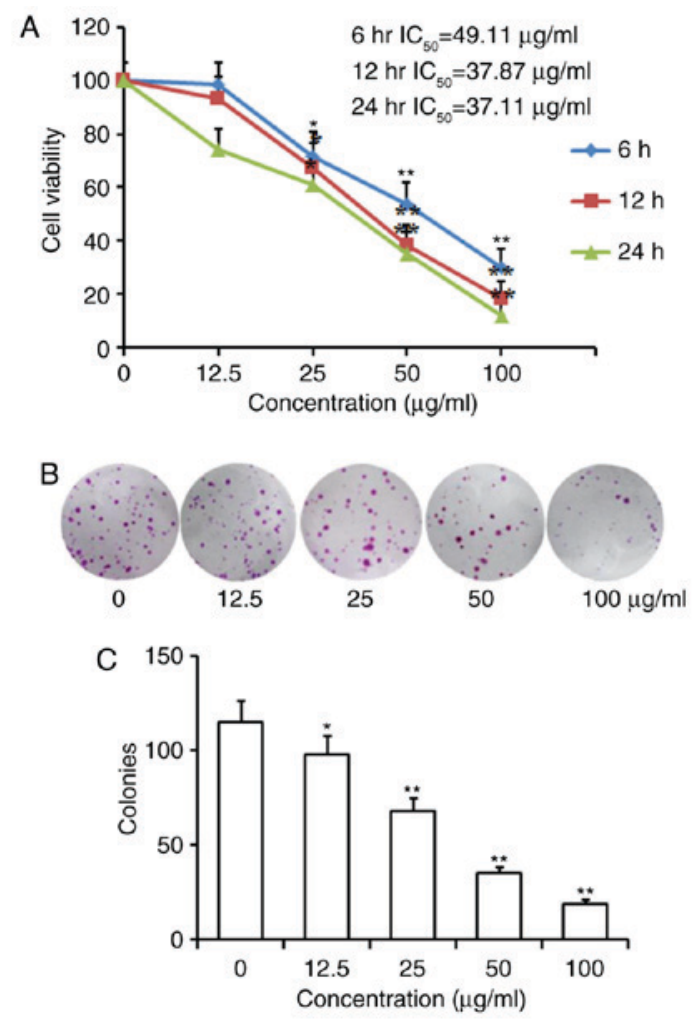

Figure 2. Homoisoflavanone-1 inhibits A549 cells proliferation and colony formation. (A) A549 cells were treated with various concentrations of homoisoflavanone-1 for 6, 12 and $24 \mathrm{~h}$. Cell viability was assessed using MTT assay. (B and C) Homoisoflavanone-1 suppressed colony formation of A549 cells. Cells were treated with homoisoflavanone-1 and then cultured in a fresh medium for 6 days to form colonies. Data are presented as the mean \pm standard deviation from three independent experiments. ${ }^{*} \mathrm{P}<0.05$ and ${ }^{* *} \mathrm{P}<0.01$ vs. control group.

effect on the growth of A549 cells was still observed at a lower concentration of homoisoflavanone-1 $(25 \mu \mathrm{g} / \mathrm{ml})$ for $12,24 \mathrm{~h}$ $(\mathrm{P}<0.05)$. The IC50 values were 49.11, 37.87 and $37.11 \mu \mathrm{g} / \mathrm{ml}$ for 6,12 and $24 \mathrm{~h}$ incubation with homoisoflavanone-1, respectively. In addition, the colony formation rate of A549 cells in homoisoflavanone-1-treated groups was obviously lower than that of the control group (Fig. 2B and C).

Homoisoflavanone-1 arrests the cell cycle between the G2/M phases in A549 cells. To address the precise action responsible for the anti-proliferative effect mediated by homoisoflavanone-1, the cell cycle distribution profile was examined. As indicated in Table II, A549 cells were exposed to $0,12.5,25,50$, or $100 \mu \mathrm{g} / \mathrm{ml}$ homoisoflavanone-1 for $24 \mathrm{~h}$. The ratio of the $\mathrm{G} 2 / \mathrm{M}$ phase was $1.07,7.34,10.13,12.75$ and 17.76 for $0,12.5,25,50$ and $100 \mu \mathrm{g} / \mathrm{ml}$, respectively. There was no difference in the proportions of cells in the G0/G1 phases, however, the proportion of cells in the $\mathrm{S}$ phase was also reduced in response to homoisoflavanone-1 treatment (Fig. 3A and B).

Homoisoflavanone-1 induces apoptosis in A549 cells. We conducted flow cytometry to evaluate the effect of homoisoflavanone-1 on A549 cell apoptosis. The results demonstrate that A549 cells treated with increasing concentrations $(12.5,25,50$ and $100 \mu \mathrm{g} / \mathrm{ml})$ of homoisoflavanone-1 over $24 \mathrm{~h}$ showed an increase in the proportion of apoptotic cells (17.22, 
Table II. Effects of homoisoflavanone-1 on the cell cycle of A549 cells.

\begin{tabular}{lcrr}
\hline Concentration $(\mu \mathrm{g} / \mathrm{ml})$ & G0/G1 phase & S phase & G2/M phase \\
\hline 0 & $55.39 \pm 2.37$ & $43.99 \pm 1.50$ & $1.07 \pm 1.11$ \\
12.5 & $57.89 \pm 2.57$ & $36.39 \pm 2.09$ & $7.34 \pm 1.31^{\mathrm{a}}$ \\
25 & $53.48 \pm 3.05$ & $36.92 \pm 1.98$ & $10.13 \pm 2.07^{\mathrm{a}}$ \\
50 & $48.54 \pm 2.97$ & $27.73 \pm 1.71^{\mathrm{a}}$ & $12.75 \pm 1.89^{\mathrm{b}}$ \\
100 & $54.52 \pm 2.86$ & $26.21 \pm 1.42^{\mathrm{a}}$ & $17.76 \pm 1.43^{\mathrm{b}}$ \\
\hline
\end{tabular}

${ }^{\mathrm{a}} \mathrm{P}<0.05,{ }^{\mathrm{b}} \mathrm{P}<0.01$ vs. controls at the same time point. Data are shown as the mean \pm standard deviation from three independent experiments.
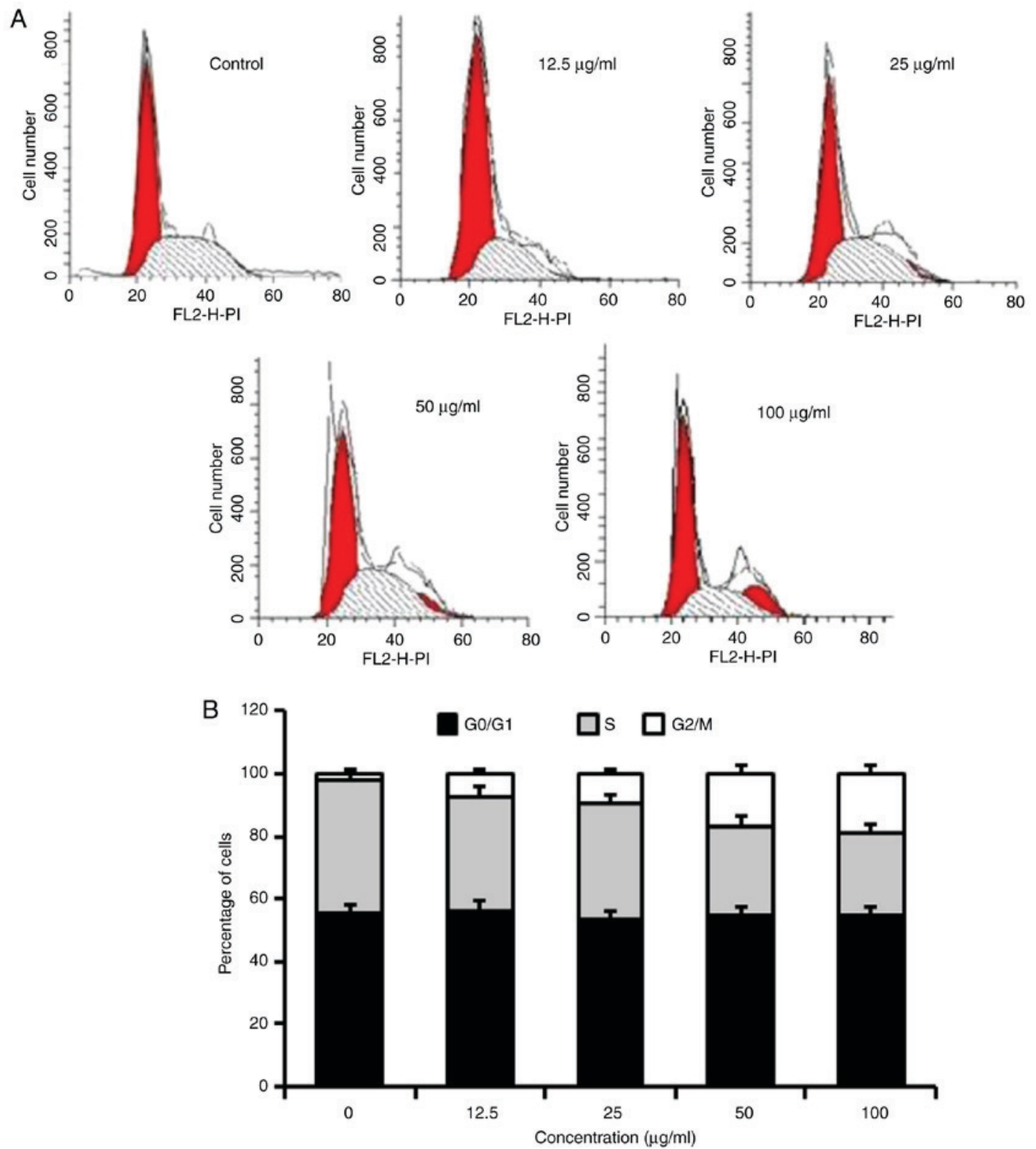

Figure 3. Homoisoflavanone-1 induces cell cycle arrest in the G2/M phase in A549 cells. (A) Flow cytometry was performed to investigate, (B) the percentage of cells at each stage of the cell cycle. This revealed the arresting effect of homoisoflavanone-1 on A549 cells. A549 cells were exposed to 0, 12.5, 25, 50 or $100 \mu \mathrm{g} / \mathrm{ml}$ homoisoflavanone- 1 for $24 \mathrm{~h}$ as indicated $(\mathrm{n}=3)$.

18.23, 25.53, and 47.12\%, respectively) (Fig. 4A and B). These data showed that homoisoflavanone-1 induced dose-dependent apoptosis in the cells and significantly increased the rate of apoptosis compared with untreated control cells (5.44\%).
Homoisoflavanone-1 regulates cell cycle-related proteins in A549 Cells. Activated p38, which is involved in various types cell differentiation, can cause mitotic arrest at the spindle assembly checkpoint in somatic cell cycle $(14,22)$. 


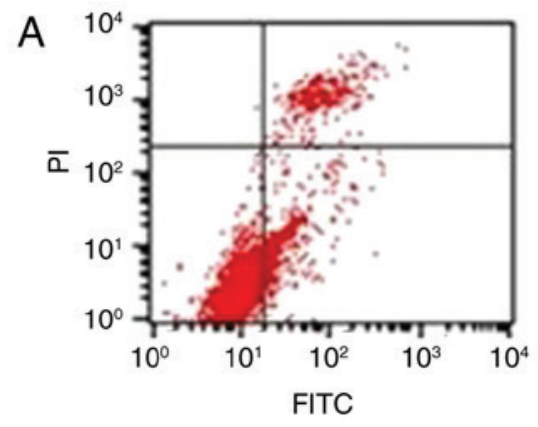

Control
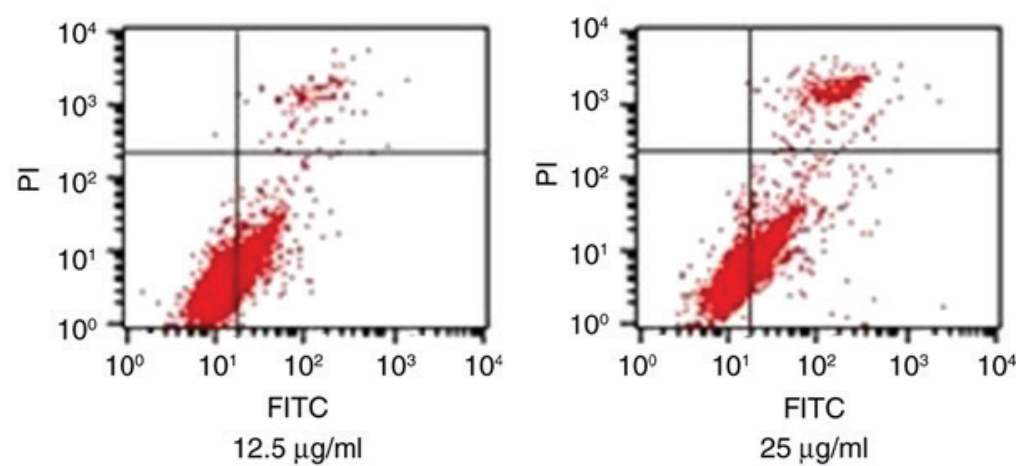

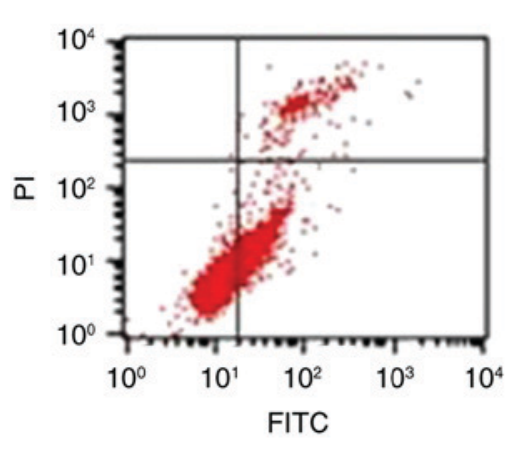

$50 \mu \mathrm{g} / \mathrm{ml}$
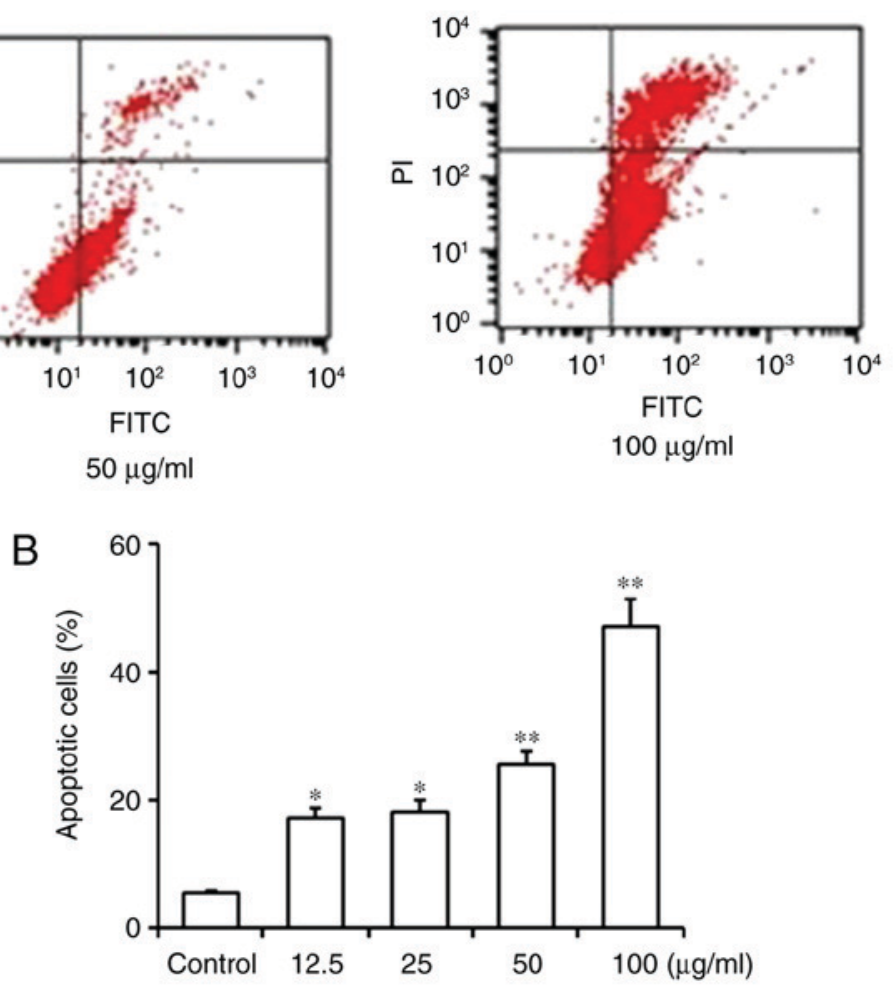

Figure 4. Homoisoflavanone-1 induces apoptosis in A549 cells. (A) A549 cells were exposed to 0, 12.5, 25, 50 or $100 \mu \mathrm{g} / \mathrm{ml}$ homoisoflavanone-1 for $24 \mathrm{~h}$, prior to analysis by (A) flow cytometry. (B) Histogram of the rate of apoptosis as determined by FACS analysis for three separate treatments. $\mathrm{P}<0.05$; ${ }^{* *} \mathrm{P}<0.01$ vs. the control. FACS, fluorescence-activated cell sorting.

Additionally, p53 is a key regulator mediating cell cycle arrest induced by a range of factors, including DNA damage and exposure to chemotherapeutic compounds (23). To investigate the molecular events governing homoisoflavanone-1-mediated cell cycle retardation, we used immunoblots to detect the protein levels of p-p38, p38 and p53 in A549 cells after $24 \mathrm{~h}$ of various doses of homoisoflavanone-1 $(0,12.5,25,50$ and $100 \mu \mathrm{g} / \mathrm{ml}$ ) treatment. As shown in Fig. 5A-D, there was a dose-dependent increase in the active forms of p-p38, p38 and p53 in response to homoisoflavanone-1 treatment.

Cdc $2 /$ cyclin B complexes initiate mitosis (M) by phosphorylating both regulatory and structural proteins involved in mitosis (24). CDK activity is itself regulated by phosphorylation and dephosphorylation, as simply binding to cyclins is not sufficient for activation of the complexes (25). As shown in Fig. 5E and F, p-Cdc2 levels increased in a dose-dependent manner in cells that were treated with homoisoflavanone-1 $(0,12.5,25,50$, and $100 \mu \mathrm{g} / \mathrm{ml})$, while $\mathrm{Cdc} 2$ levels decreased.
Homoisoflavanone-1 induces intrinsic mitochondriamediated apoptosis. As an effector caspase, caspase-3 remains inactive until apoptotic signaling leads to its cleavage by an initiator caspase (26). Poly ADP-ribose polymerase (PARP) is cleaved between Asp214 and Gly215 by the activated caspase-3, which leads to PARP inactivation and further facilitates apoptotic cell death. As shown in Fig. 6A-D, the amount of caspase 3 and active caspase-3 proteins increased dramatically in a dose-dependent manner after cells were treated with high concentrations of homoisoflavanone-1 $(25,50$ and $100 \mu \mathrm{g} / \mathrm{ml})$, while the amount of PARP protein decreased.

Bcl-2 proteins regulate caspase activity, and function in intrinsic mitochondrion-mediated apoptosis (27). Within the Bcl-2 family, Bcl-2 is anti-apoptotic, whereas Bak is pro-apoptotic (28). After treatment with various concentrations of homoisoflavanone-1, the amount of $\mathrm{Bcl}-2$ protein decreased significantly, whereas the amount of Bak protein increased in a dose-dependent manner (Fig. 6E and F). 

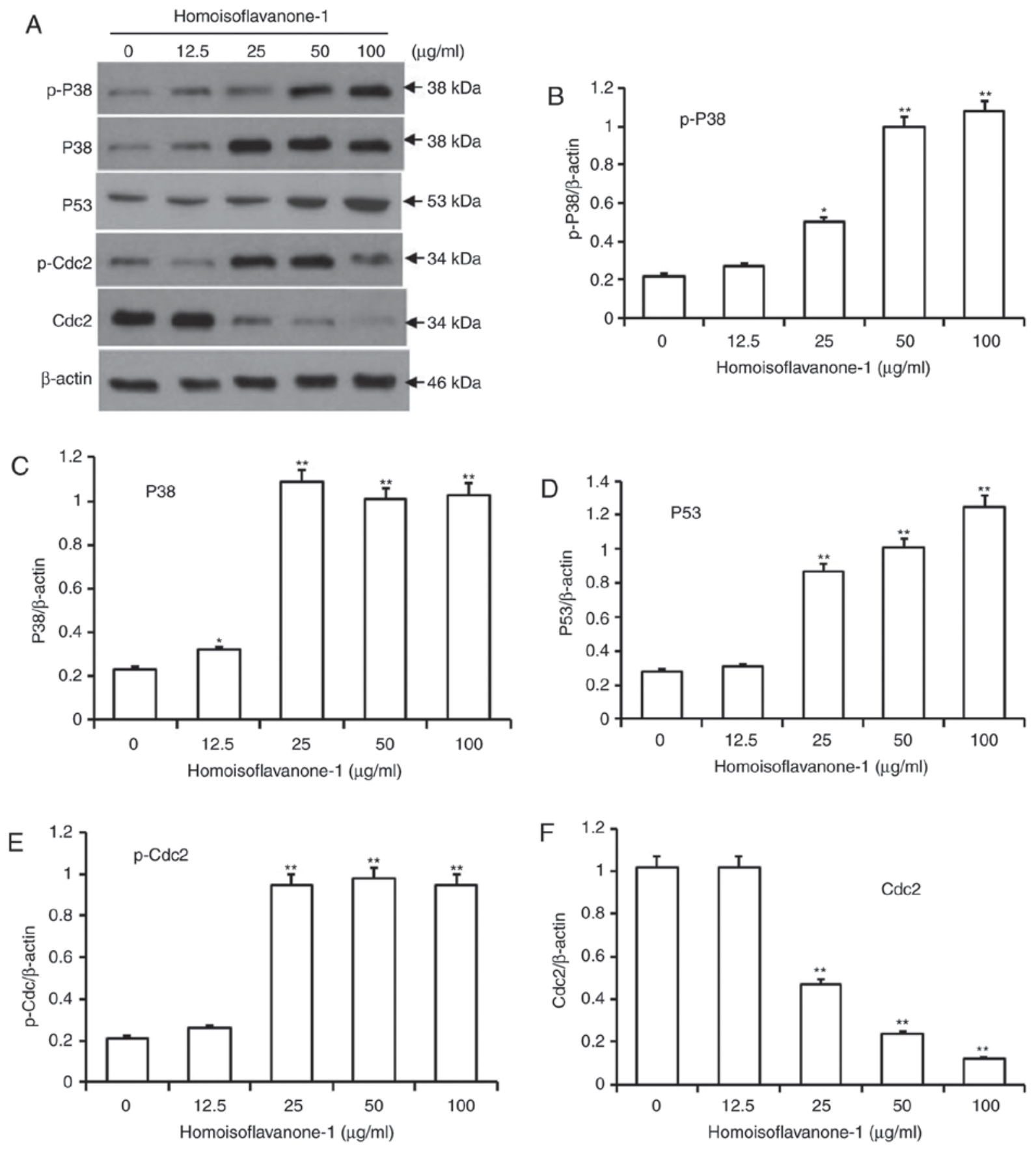

Figure 5. Accumulation of cell-cycle associated proteins in response to homoisoflavanone-1 treatment. (A) A549 cells were treated with $0,12.5,25,50$ and $100 \mu \mathrm{g} / \mathrm{ml}$ homoisoflavanone-1 for $24 \mathrm{~h}$ and analyzed by western blot analysis. Immunoblotting detected the protein expression of (B) p-p38, (C) p38, (D) p53, (E) $\mathrm{p}$-Cdc2 and (F) Cdc2. $\beta$-actin was the loading control. Data are presented as the mean \pm standard deviation from three independent experiments. ${ }^{*} \mathrm{P}<0.05$ and ${ }^{* *} \mathrm{P}<0.01$ vs. the control group. Cdc, cyclin dependent kinase.

Homoisoflavanone-1 treatment increased the abundance of er stress-related proteins. To further examine homoisoflavanone-1 induced apoptosis in A549 cells, we assessed the expressions of the ER stress-related proteins PERK, ATF4, and GADD34 in homoisoflavanone-1 treated cells. As shown in Fig. 7A and B, phomoisoflavanone-1 $(100 \mu \mathrm{g} / \mathrm{ml})$ significantly increased the abundance of ER stress-related proteins in a time-dependent manner. PERK levels peaked $12 \mathrm{~h}$ after homoisoflavanone-1 treatment, while ATF4 and GADD34 reached a peak at $24 \mathrm{~h}$ with the same treatment. Homoisoflavanone-1 also increased the expression of these three proteins in a dose-dependent manner at both 12 and $24 \mathrm{~h}$ (Fig. 7C-F). These results suggest that the ER stress pathway functions in homoisoflavanone-1-induced lung cancer cell apoptosis.

\section{Discussion}

Homoisoflavanone-1 is a natural product that can be purified from $P$. odoratum, a traditional herbal medicine due to its anti-hyperglycemic effects (16), procoagulant activity (15), and apoptosis inducing activity $(17,29)$. In the present study, we demonstrated that homoisoflavanone-1 exerted anti-cancer 

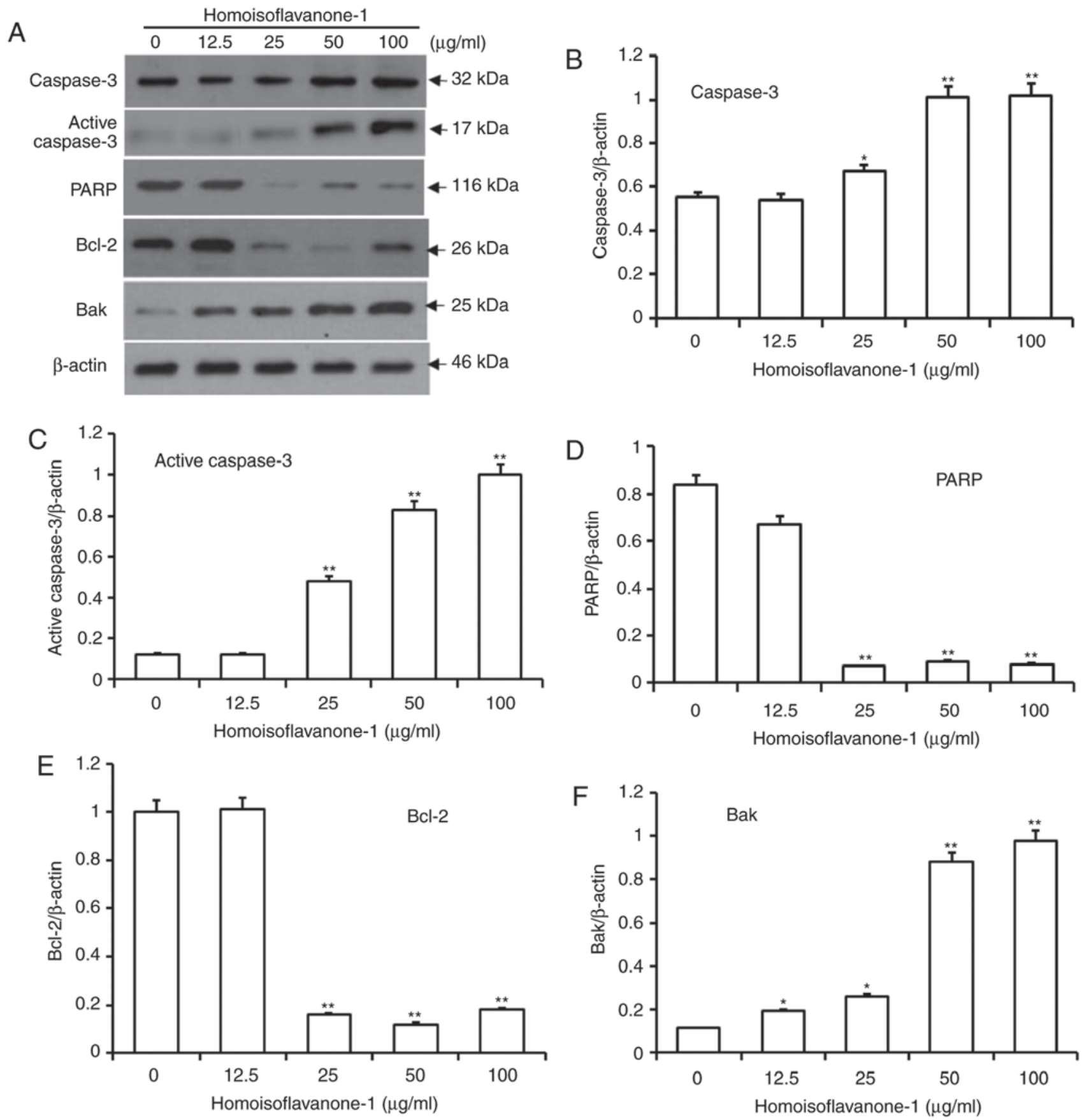

Figure 6. Accumulation of proteins associated with the mitochondria-caspase pathway for apoptosis in response to homoisoflavanone-1 treatment. (A) A549 cells were treated with $0,12.5,25,50$ and $100 \mu \mathrm{g} / \mathrm{ml}$ of homoisoflavanone-1 for 24 and analyzed by western blotting. Immunoblotting detected the protein expression of (B) caspase 3, (C) active caspase 3, (D) PARP, (E) Bcl-2 and (F) Bak. $\beta$-actin was the loading control. Data are presented as the mean \pm standard deviation from three independent experiments. ${ }^{*} \mathrm{P}<0.05$ and ${ }^{* *} \mathrm{P}<0.01$ vs. the control group. PARP, poly ADP-ribose polymerase; Bcl-2, B-cell lymphoma 2.

activity by reducing the viability of A549 cells, and that this activity was associated with cell cycle arrest and apoptosis. Moreover, homoisoflavanone-1 activated the mitochondrion and ER stress apoptotic pathways in A549 cells, concomitant with changes in the cell cycle and the expression of apoptosis-related proteins.

Cell cycle progression from $\mathrm{G} 2$ to $\mathrm{M}$ is regulated by cyclin $\mathrm{B} / \mathrm{Cdc} 2$, which is a component of the mitosis-promoting factor (MPF) (30). To move past the M phase, the cyclin $\mathrm{B} / \mathrm{Cdc} 2$ must be inactivated by the cyclin-CDK complex bound to p21 (31). Interestingly, p53 is upstream of p21 in this cascade, and regulates it at the transcriptional level (32). Then, active p38 can induce p53 and p21 activation, at least in part by increasing ROS levels. Upregulated p38 expression can also promote $\mathrm{Cdc} 2$ phosphorylation, which inhibits the transcription of cyclin $B 1$ and $C d c 2$ and therefore reduces the levels of the $\mathrm{Cdc} 2 /$ cyclin $\mathrm{B} 1$ complex required for progression from $\mathrm{G} 2$ to $\mathrm{M}$ (33). Our findings of increased levels of P-P38, p38, p53 and p-Cdc2, and decreased levels of $\mathrm{Cdc} 2$, suggest that these proteins are involved in the homoisoflavanone-1-induced $\mathrm{G} 2 / \mathrm{M}$ arrest by activating the p38-p53 signaling pathway. 

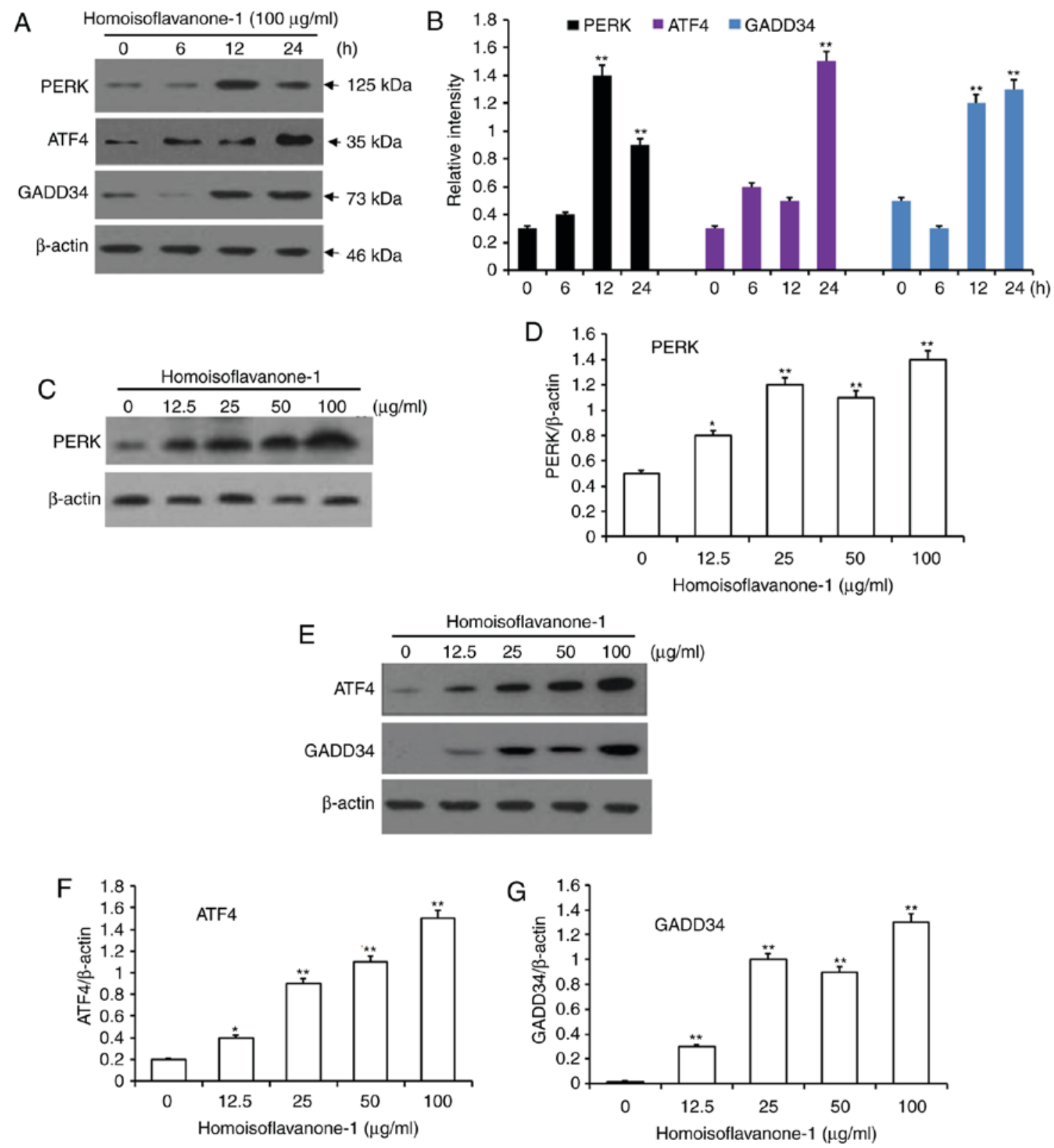

Figure 7. Accumulation of proteins associated with the ER stress pathway for apoptosis in response to homoisoflavanone-1 treatment. A549 cells were treated with homoisoflavanone-1 (100 $\mu \mathrm{g} / \mathrm{ml})$ for 0,6,12 and $24 \mathrm{~h}$. (A) Western blot analysis was performed to detect the protein expression of (B) PERK, ATF4 and GADD34. A549 cells were treated with $0,12.5,25,50$ or $100 \mu \mathrm{g} / \mathrm{ml}$ of homoisoflavanone- 1 for $12 \mathrm{~h}$ and (C) western blot analysis was performed to detect the protein expression of (D) PERK. A549 cells were treated with 0, 12.5, 25, 50 or $100 \mu \mathrm{g} / \mathrm{ml}$ of homoisoflavanone-1 for $24 \mathrm{~h}$ and (E) western blot analysis was performed to detect the protein expression of (F) ATF4 and (G) GADD34. $\beta$-actin was the loading control. Data are presented as the mean \pm standard deviation from three independent experiments. ${ }^{*} \mathrm{P}<0.05$ and ${ }^{* *} \mathrm{P}<0.01$ vs. the control group. ER, endoplasmic reticulum.

As a process in programmed cell death, apoptosis is necessary for cell growth, development, and homeostasis in metazoans associated with G2/M arrest $(34,35)$. Three well-studied pathways initiate apoptosis: the mitochondrion-mediated intrinsic pathway, the ER stress-induced pathway, and the death receptor-induced extrinsic pathway (36). In the mitochondria-mediated intrinsic pathway, apoptosis is mediated primarily by Bcl-2 family proteins including anti-apoptotic proteins such as Bcl-2 and pro-apoptotic proteins such as Bak. Altering the balance between Bcl-2 and Bak can increase permeability of the mitochondrial outer membrane, leading to cytochrome c release, and ultimately activate caspase cascades $(37,38)$. In addition, ligands in the extrinsic pathway induce the caspase- 8 initiator protease, which activates effector proteases such as caspase-3 (39,40). Active caspase-3 cleaves PARP, a nuclear DNA repair enzyme involved maintaining genomic integrity, which further facilitates apoptotic cell death $(41,42)$. In the present study, flow cytometric analysis showed homoisoflavanone-1 induced apoptosis in A549 cells. This was further supported by a reduced $\mathrm{Bcl}-2 / \mathrm{Bak}$ ratio, reflecting by increase in Bak and a decrease in Bcl-2. Together, these data indicate that homoisoflavanone-1 affects the response to mitochondrial-mediated apoptosis. Moreover, homoisoflavanone-1 treatment resulted in an increase in active caspase- 3 levels and a decrease in PARP levels, which suggests that homoisoflavanone-1 also induced caspase-associated cell apoptosis. 
ER stress-induced cancer cell apoptosis is a high-profile signaling target for the development of cancer therapy drugs. When the cell is under reactive oxygen and calcium ion stress, the ER stress pathway is induced by unfolded or misfolded protein accumulation in the ER lumen (43). Activated PERK is an important sensor for ER stress. When ER stress occurs, the downstream signaling pathway is induced and inhibits protein translation, consequently restoring ER homeostasis (44). As ER stress increases and/or time passes, the PERK signaling pathway activates ATF4 (45), which in turn drives growth arrest and transcription of DNA damage-inducible 34 (GADD34). Continued expression of GADD34 will then induce cell death (46). Consistent with the present study, the protein levels of PERK peaked $12 \mathrm{~h}$ after homoisoflavanone-1 (100 mg/l) treatment, while ATF4 and GADD34 peaked $24 \mathrm{~h}$ after the same treatment. In addition, we observed an increase in abundance of the ER stress-related proteins PERK, ATF4, and GADD34 in a dose-dependent manner, indicating that ER stress was activated in response to homoisoflavanone-1 treatment in A549 cells.

In conclusion, our study presents the first evidence of a role for homoisoflavanone-1 in inducing cell cycle arrest and in promoting apoptosis in NSCLC A549 cells and reveals that homoisoflavanone-1 accomplishes this by regulating the mitochondrion-caspase-dependent and ER stress pathways. These findings suggest that homoisoflavanone-1 extracted from $P$. odoratum may function as a tumor suppressor and has potential as a therapeutic agent to treat lung cancer.

\section{Acknowledgements}

Not applicable.

\section{Funding}

The present study was supported by Scientific Research Fund of Heilongjiang Provincial Education Department (grant no. 2016-KYYWF-0859).

\section{Availability of data and materials}

All data generated or analyzed during this study are included in this published article.

\section{Authors' contributions}

DN participated in the study design and all experimental procedures as well as drafting the manuscript. MJ and TX and JS performed the experiments. ML performed protein identification. All authors read and approved the final manuscript.

\section{Ethics approval and consent to participate}

Not applicable.

\section{Patient consent for publication}

Not applicable.

\section{Competing interests}

The authors declare that they have no competing interests.

\section{References}

1. Kohler BA, Ward E, McCarthy BJ, Schymura MJ, Ries LA, Eheman C, Jemal A, Anderson RN, Ajani UA and Edwards BK: Annual report to the nation on the status of cancer, 1975-2007, featuring tumors of the brain and other nervous system. J Natl Cancer Inst 103: 714-736, 2011.

2. Wallace WA: The challenge of classifying poorly differentiated tumours in the lung. Histopathology 54: 28-42, 2009.

3. Smith SL, Palma D, Parhar T, Alexander CS and Wai ES: Inoperable early stage non-small cell lung cancer: Comorbidity, patterns of care and survival. Lung Cancer 72 : 39-44, 2011.

4. Zhao D, Yang G, Meng Q, Liu J and Yang S: Linobiflavonoid inhibits human lung adenocarcinoma A549 cells: Effect on tubulin protein. Mol Biol Rep 40: 6019-6025, 2013.

5. Jemal A, Bray F, Center MM, Ferlay J, Ward E and Forman D: Global cancer statistics. CA Cancer J Clin 61: 69-90, 2011.

6. Elmore S: Apoptosis: A review of programmed cell death. Toxicol Pathol 35: 495-516, 2007.

7. Fang C, Zhang J, Qi D, Fan X, Luo J, Liu L and Tan Q: Evodiamine induces G2/M arrest and apoptosis via mitochondrial and endoplasmic reticulum pathways in H446 and H1688 human small-cell lung cancer cells. PLoS One 9: e115204, 2014.

8. Martinvalet D, Zhu P and Lieberman J: Granzyme A induces caspase-independent mitochondrial damage, a required first step for apoptosis. Immunity 22: 355-370, 2005.

9. Dejean LM, Martinez-Caballero S, Manon S and Kinnally KW: Regulation of the mitochondrial apoptosis-induced channel, MAC, by BCL-2 family proteins. Biochim Biophys Acta 1762: 191-201, 2006.

10. Scorrano L, Oakes SA, Opferman JT, Cheng EH, Sorcinelli MD, Pozzan $\mathrm{T}$ and Korsmeyer SJ: BAX and BAK regulation of endoplasmic reticulum $\mathrm{Ca} 2+$ : A control point for apoptosis. Science 300: 135-139, 2003.

11. Wang XZ and Ron D: Stress-induced phosphorylation and activation of the transcription factor CHOP (GADD153) by p38 MAP Kinase. Science 272: 1347-1349, 1996.

12. Kim BJ, Ryu SW and Song BJ: JNK- and p38 kinase-mediated phosphorylation of Bax leads to its activation and mitochondrial translocation and to apoptosis of human hepatoma HepG2 cells. J Biol Chem 281: 21256-21265, 2006.

13. Hetz C, Bernasconi P, Fisher J, Lee AH, Bassik MC, Antonsson B, Brandt GS, Iwakoshi NN, Schinzel A, Glimcher LH and Korsmeyer SJ: Proapoptotic BAX and BAK modulate the unfolded protein response by a direct interaction with IRElalpha. Science 312: 572-576, 2006.

14. Takenaka K, Moriguchi T and Nishida E: Activation of the protein kinase p38 in the spindle assembly checkpoint and mitotic arrest. Science 280: 599-602, 1998.

15. Zhang H, Chen L, Kou JP, Zhu DN, Qi J and Yu BY: Steroidal sapogenins and glycosides from the fibrous roots of Polygonatum odoratum with inhibitory effect on tissue factor (TF) procoagulant activity. Steroids 89: 1-10, 2014.

16. Deng Y, He K, Ye X, Chen X, Huang J, Li X, Yuan L, Jin Y, Jin Q and Li P: Saponin rich fractions from Polygonatum odoratum (Mill.) Druce with more potential hypoglycemic effects. J Ethnopharmacol 141: 228-233, 2012.

17. Yang Y, Xu HL, Zhang ZT, Liu JJ, Li WW, Ming H and Bao JK: Characterization, molecular cloning, and in silico analysis of a novel mannose-binding lectin from Polygonatum odoratum (Mill.) with anti-HSV-II and apoptosis-inducing activities. Phytomedicine 18: 748-755, 2011.

18. Park S, Hong SM, Ahn IS, Kim YJ and Lee JB: Huang-Lian-Jie-Du-Tang supplemented with Schisandra chinensis Baill. and Polygonatum odoratum Druce improved glucose tolerance by potentiating insulinotropic actions in islets in $90 \%$ pancreatectomized diabetic rats. Biosci Biotechnol Biochem 73: 2384-2392, 2009.

19. Wang D, Zeng L, Li D and Pu W: Antioxidant activities of different extracts and homoisoflavanones isolated from the Polygonatum odoratum. Nat Prod Res 27: 1111-1114, 2013. 
20. Guo H, Zhao H, Kanno Y, Li W, Mu Y, Kuang X, Inouye Y, Koike $\mathrm{K}$, Jiang $\mathrm{H}$ and Bai $\mathrm{H}$ : A dihydrochalcone and several homoisoflavonoids from Polygonatum odoratum are activators of adenosine monophosphate-activated protein kinase. Bioorg Med Chem Lett 23: 3137-3139, 2013.

21. Bloom J and Cross FR: Multiple levels of cyclin specificity in cell-cycle control. Nat Rev Mol Cell Biol 8: 149-160, 2007.

22. Nebreda AR and Porras A: p38 MAP kinases: Beyond the stress response. Trends Biochem Sci 25: 257-260, 2000.

23. El-Deiry WS: The role of p53 in chemosensitivity and radiosensitivity. Oncogene 22: 7486-7495, 2003.

24. Malumbres M: Physiological relevance of cell cycle kinases. Physiol Rev 91: 973-1007, 2011.

25. Morgan DO: Cyclin-dependent kinases: Engines, clocks, and microprocessors. Annu Rev Cell Dev Biol 13: 261-291, 1997.

26. Walters J, Pop C, Scott FL, Drag M, Swartz P, Mattos C, Salvesen GS and Clark AC: A constitutively active and uninhibitable caspase-3 zymogen efficiently induces apoptosis. Biochem J 424: 335-345, 2009.

27. Youle RJ and Strasser A: The BCL-2 protein family: Opposing activities that mediate cell death. Nat Rev Mol Cell Biol 9: 47-59, 2008

28. Harris $\mathrm{MH}$ and Thompson CB: The role of the Bcl-2 family in the regulation of outer mitochondrial membrane permeability. Cell Death Differ 7: 1182-1191, 2000.

29. Ouyang L, Chen Y, Wang XY, Lu RF, Zhang SY, Tian M, Xie T, Liu B and He G: Polygonatum odoratum lectin induces apoptosis and autophagy via targeting EGFR-mediated Ras-Raf-MEK-ERK pathway in human MCF-7 breast cancer cells. Phytomedicine 21: 1658-1665, 2014

30. Arion D, Meijer L, Brizuela L and Beach D: cdc2 is a component of the M phase-specific histone H1 kinase: Evidence for identity with MPF. Cell 55: 371-378, 1988.

31. Bloom J and Pagano M: To be or not to be ubiquitinated? Cell Cycle 3: 138-140, 2004

32. Bates S, Ryan KM, Phillips AC and Vousden KH: Cell cycle arrest and DNA endoreduplication following p21Waf1/Cip1 expression. Oncogene 17: 1691-1703, 1998.

33. Kang N, Jian JF, Cao SJ, Zhang Q, Mao YW, Huang YY, Peng YF, Qiu F and Gao XM: Physalin A induces G2/M phase cell cycle arrest in human non-small cell lung cancer cells: Involvement of the p38 MAPK/ROS pathway. Mol Cell Biochem 415: 145-155, 2016.

34. Fuchs Y and Steller H: Programmed cell death in animal development and disease. Cell 147: 742-758, 2011.
35. Green DR, Galluzzi L and Kroemer G: Cell biology. Metabolic control of cell death. Science 345: 1250256, 2014.

36. Beere HM: Death versus survival: Functional interaction between the apoptotic and stress-inducible heat shock protein pathways. J Clin Invest 115: 2633-2639, 2005.

37. Wang $\mathrm{C}$ and Youle RJ: The role of mitochondria in apoptosis*. Annu Rev Genet 43: 95-118, 2009.

38. Zhang F, Kong DS, Zhang ZL, Lei N, Zhu XJ, Zhang XP, Chen L, Lu Y and Zheng SZ: Tetramethylpyrazine induces G0/G1 cell cycle arrest and stimulates mitochondrial-mediated and caspase-dependent apoptosis through modulating ERK/p53 signaling in hepatic stellate cells in vitro. Apoptosis 18: 135-149, 2013.

39. Cardile V, Musumeci G, Sicurezza E, Caggia S, Rusu MC, Leonardi R and Loreto C: Expression of TRAIL and its receptors DR5 and DcR2 in orthodontic tooth movement. Histol Histopathol 28: 933-940, 2013.

40. Musumeci G, Loreto C, Leonardi R, Castorina S, Giunta S, Carnazza ML, Trovato FM, Pichler K and Weinberg AM: The effects of physical activity on apoptosis and lubricin expression in articular cartilage in rats with glucocorticoid-induced osteoporosis. J Bone Miner Metab 31: 274-284, 2013.

41. Shakibaei M, Csaki C, Nebrich S and Mobasheri A: Resveratrol suppresses interleukin-1beta-induced inflammatory signaling and apoptosis in human articular chondrocytes: Potential for use as a novel nutraceutical for the treatment of osteoarthritis. Biochem Pharmacol 76: 1426-1439, 2008.

42. Virág L and Szabó C: The therapeutic potential of poly(ADP-ribose) polymerase inhibitors. Pharmacol Rev 54: 375-429, 2002.

43. Boyce M and Yuan J: Cellular response to endoplasmic reticulum stress: A matter of life or death. Cell Death Differ 13: 363-373, 2006.

44. Wang J, Hu X and Jiang H: ERS-PERK signaling pathwaymediated Nrf2/ARE-HO-1 axis: A novel therapeutic target for attenuating myocardial ischemia and reperfusion injury. Int J Cardiol 203: 779-780, 2016.

45. Harding HP, Novoa I, Zhang Y, Zeng H, Wek R, Schapira M and Ron D: Regulated translation initiation controls stress-induced gene expression in mammalian cells. Mol Cell 6: 1099-1108, 2000 .

46. Sano R and Reed JC: ER stress-induced cell death mechanisms. Biochim Biophys Acta 1833: 3460-3470, 2013. 